\title{
MicroRNA-301b promotes cell invasiveness through targeting TP63 in pancreatic carcinoma cells
}

\author{
NAOTAKE FUNAMIZU ${ }^{1}$, CURTIS RAY LACY ${ }^{2}$, SONYA T. PARPART ${ }^{3}$, ATSUSHI TAKAI ${ }^{4}$, \\ YUKIHARU HIYOSHI ${ }^{5}$ and KATSUHIKO YANAGA ${ }^{1}$
}

\author{
${ }^{1}$ Department of Surgery, The Jikei University School of Medicine, Tokyo, Japan; ${ }^{2}$ Howard University \\ School of Medicine; ${ }^{3}$ Georgetown University, Washington DC, USA; ${ }^{4}$ Department of Gastroenterology, \\ Kyoto University, Kyoto; ${ }^{5}$ Department of Surgery, Kumamoto University, Kumamoto, Japan
}

Received September 20, 2013; Accepted November 6, 2013

DOI: $10.3892 /$ ijo.2014.2243

\begin{abstract}
Recent studies have demonstrated that deregulated microRNA (miR) expression is implicated in the development of human cancers. In the aberrant miR expression, miR-301 is upregulated in cancers, such as pancreatic, colorectal and oral carcinoma. Based on this evidence, we investigated the contribution of miR-301 to pancreatic carcinoma and the novel target genes of miR-301 in pancreatic carcinoma. In this study, we analyzed the effects of enforced and inhibited expression of miR-301b expression in the Panc-1 and BxPC-3 cell lines. MiR-301b expression levels were associated with cell invasiveness in both cell lines. Additional experiments indicated that miR-301b influences invasiveness through CDH1. Moreover microRNA target search algorithms and experimental strategies suggested that miR-301b suppressed TP63 expression as a novel target of miR-301b. Remarkably, miR-301b was also found to be associated with $\mathrm{NF}-\kappa \mathrm{B}$ activity in both cell lines. In summary, overexpressed miR-301b may suppress TP63 expression and contributes to promote cell invasiveness and to enhance gemcitabine resistance in pancreatic carcinoma cells. Thus, miR-301b may have potential as a novel therapeutic target for cancer treatment due to its stimulatory effects on cell invasiveness.
\end{abstract}

\section{Introduction}

Pancreatic carcinoma is the fourth leading cause of cancer mortality in the United States, with an incidence of 43,000 new cases per year and a very high mortality with 37,000 deaths (1). Patients with pancreatic carcinoma usually present with advanced stage. Despite new drugs and therapeutic regimens with gemcitabine, the prognosis of patients with

Correspondence to: Dr Naotake Funamizu, Department of Surgery, The Jikei University School of Medicine, 3-25-8 Nishi-shinbashi, Minato-ku, Tokyo 105-8461, Japan

E-mail: funamizujikei@yahoo.co.jp

Key words: pancreatic carcinoma, micro-RNA-301b, TP63 pancreatic carcinoma has not significantly changed in the last decades (2). Surgical resection still remains the main therapy for pancreatic carcinoma, but a large fraction of patients cannot undergo curative resection (3). Moreover, molecular mechanisms including cancer development and progression are still unclear. Thus, innovative therapeutic targets and prognostic markers are urgently needed for pancreatic carcinoma treatment.

MicroRNAs (miRNAs) represent a novel class of naturally occurring small non-coding RNA molecules, which are evolutionarily conserved. Mature miRNAs are approximately short 22-nucleotide molecules. The mature single-stranded miRNAs bind to specific targets in mRNA 3'-untranslated regions (3'-UTRs) and negatively regulate translation or mRNA cleavage through partial sequence homology (4). Accumulated evidence in cancer biology has shown frequent deregulation of miRNAs in human malignancies (5-7). Deregulated miRNAs play an important role in behaving as either oncogenes or tumor suppressor genes, and some of miRNAs have been implicated in cellular processes of proliferation, apoptosis and chemoresistance (8-10).

Among these miRNAs, miR-301 has been reported to be upregulated in various cancers, including pancreatic, colorectal, oral, hepatocellular and lung cancers (11-15). Recently, miR-301a was revealed to regulate MEOX2, which is known to be associated with ERK/CREB pathway in lung cancer (16). Subsequently, miR-301 was implicated in cell proliferation, clonogenicity, migration, invasion, tamoxifen resistance, tumor growth and microvessel density. Moreover, a study identified FOXF2, BBC3, PTEN and COL2A1 as candidate miR-301 targets in breast cancer (17). More recently, other researchers have shown that miR-301a is associated with $\mathrm{NF}-\kappa \mathrm{B}$ activity through targeting $\mathrm{NF}-\kappa \mathrm{B}$ repressing factor (NKRF) in pancreatic carcinoma (18). These results could indicate that miR-301 may be a new class of genes involved in human oncogenesis.

In this study, we aimed to investigate the mechanistic role of miR-301b expression in pancreatic carcinoma and to identify new target genes of miR-301b. We found that miR$301 \mathrm{~b}$ could promote cell invasion and migration in Panc-1 and BxPC-3. In addition, we showed that the transfection of synthetic miR-301b increased drug resistance to gemcitabine. 
The miR-301b was examined for potential 3'UTR-binding sites utilizing miRNA target search algorithms, which is TargetScan (http://genes.mit.edu/targetscan/) and microRNA. org (http://www.microrna.org/).

This result revealed that TP63 is one of the candidates as a target of miR-301b. Inverse correlation between miR-301b and TP63 was observed in five different pancreatic carcinoma cell lines. The results imply that miR-301b has functions as an oncogene and that its inhibition may have therapeutic potential roles for treatment of pancreatic carcinoma and is a predictive marker of response to chemotherapy in patients with pancreatic carcinoma.

\section{Materials and methods}

Oligonucleotides. Pre-miR-301b, negative control, miR-301b inhibitor and its negative control were purchased from Ambion (Tokyo, Japan). TP63-shRNA and negative control were purchased from Invitrogen (Tokyo, Japan).

Cell lines and cell culture conditions. Pancreatic carcinoma cell lines (Panc-1 and BxPC-3) were obtained from the American Type Culture Collection (Rockville, MD, USA). Panc-1 was maintained in Dulbecco's modified Eagle's medium (DMEM) supplemented with $10 \%$ fetal bovine serum (FBS). BxPC-3 cells were grown in RPMI-1640 with 10\% FBS. Both media contained antibiotics $(100 \mathrm{U} / \mathrm{ml}$ penicillin and $100 \mu \mathrm{g} / \mathrm{ml}$ streptomycin). All cell lines were routinely passaged as monolayer cultures at $37^{\circ} \mathrm{C}$ in a humidified atmosphere of $95 \%$ air and $5 \% \mathrm{CO}_{2}$.

MiR-301b or miR-301b inhibitor transfection experiments. MiRNA precursor molecules corresponding to miR-301b and miR-301b inhibitor were transfected using the RNAiMAX Transfection Reagent (Invitrogen) into Panc-1 and BxPC-3, and the effects on respective oligonucleotide were measured by quantitative real-time PCR. Panc-1 and BxPC- 3 cells were transfected with $50 \mathrm{nM}$ microRNA in a 6-well plate for RNA extraction or a $10-\mathrm{cm}$ dish for wound healing, proliferation and invasion assays following the manufacturer's protocol. Cells in the 6-well plate were collected $48 \mathrm{~h}$ after transfection to extract RNA and measured for miR-301b expression. After 12-h transfection, transfected cells in the $10-\mathrm{cm}$ dish were seeded in 96-well plates for wound healing and proliferation, or Matrigel coated wells for invasion assays. These premiRNA and inhibitor transfection experiments were repeated independently three times.

RNA preparation and real-time PCR analysis. Total cellular RNA was extracted from cultured cells using TRIzol (Invitrogen) according to the manufacturer's instructions. Cell pellets were suspended in an aliquot of $1 \mathrm{ml} / \mathrm{well}$ of TRIzol in a 6-well plate. Isolated RNA $(6 \mu \mathrm{g})$ was used for reverse transcription into cDNA (GE Health Care, Buckinghamshire, UK). Random primers (6-mer) were used according to the manufacturer's protocol. cDNA was diluted and stored at $-20^{\circ} \mathrm{C}$ until use. Gene expression levels were measured with custom-designed, TaqMan real-time polymerasechain reaction (Applied Biosystems, Foster City, CA, USA) containing probes to 6 genes: CDH1 (ID: Hs00156401_m1),
TP63 (ID: Hs00174164_m1), IkB- $\alpha$ (ID: Hs00355671_g1) and miR-301b (ID: 002392) with GAPDH (ID: Hs99999901_s1) for mRNA or RNAU6 (ID: 001002) for miRNA as an internal control. The relative expression levels of genes and miR-301b, relative to GAPDH or RNAU6, were calculated using the relative quantification $\Delta \Delta \mathrm{Ct}$ method. Each sample was assayed in triplicate.

Gemcitabine sensitivity assay with transfection of pre$m i R-301 b$ or miR-301b inhibitor. The drug sensitivity assay was performed essentially as described in our previous report (19). Briefly, cells were seeded in a $6-\mathrm{cm}$ dish at $70 \%$ confluency. After $12 \mathrm{~h}$, pre-miR-301b or miR-301b inhibitor and respective controls were transfected in each dish overnight. Then transfected cells were seeded in 96-well plates at 4,000 cells/well in triplicate. After incubating for $12 \mathrm{~h}$, cell viability was determined by treating cells with stepwise 4-fold serial dilutions of gemcitabine (from $100 \mu \mathrm{M}$ ) and incubated at $37^{\circ} \mathrm{C}$ for $96 \mathrm{~h}$. To evaluate cell viability, the cells were fixed with $25 \%$ glutaraldehyde for $30 \mathrm{~min}$ at room temperature and then stained with $200 \mu 1$ of $0.05 \%$ methylene blue for $20 \mathrm{~min}$. The dye was eluted with $0.33 \mathrm{M} \mathrm{HCl}$ for 20 min with agitation. Absorbance was measured in a microplate reader (model 3550, Bio-Rad, Tokyo, Japan) at $598 \mathrm{~nm}$. The $50 \%$ inhibitory concentration for cell growth $\left(\mathrm{IC}_{50}\right)$ was calculated.

Cell invasion assay. Invasion assay was performed in 24-well Biocoat Matrigel invasion chambers (Becton-Dickinson) according to the manufacturer's protocol. Briefly, cells were transfected with pre-miR-301b or miR-301b inhibitor and each negative control in 10-cm dish. After 12-h transfection, cells were harvested and plated in the Matrigel coated wells (4 or $5 \times 10^{4} /$ well) and control insert wells (4 or $5 \times 10^{4} /$ well) using Panc-1 and BxPC-3 cells, respectively. After 20-h incubation, the invasive cells through the membrane were fixed with methanol for $5 \mathrm{~min}$ and stained by crystal violet for $5 \mathrm{~min}$. Then under a microscope (x20 magnification), invaded cells were counted in 3 random fields. All assays were performed in triplicate.

Wound healing assay. Transfected cells were seeded in a 6-well plate at $80 \%$ confluency, after $12 \mathrm{~h}$, the monolayer of cells was scratched with $20 \mu 1$ pipette tip across the center of the well. After scratching, each well was gently washed with medium to remove the cell debris. Cells were then grown in appropriate medium. The cells were allowed to close the wound for $48 \mathrm{~h}$. Photographs were taken at 0, 12, 24 and 36 or $48 \mathrm{~h}$ at the same position of the wound in both Panc-1 and BxPC-3 cells.

Immunofluorescence. Cells were seeded into chamber slide at $40 \%$ confluent. After incubation overnight, pre-miR-301b or miR-301b inhibitor or negative control $(50 \mathrm{nM})$ oligonucleotides were transfected for $48 \mathrm{~h}$ as described above. Cells were fixed in 4\% paraformaldehyde for $20 \mathrm{~min}$. For permeabilization, $0.15 \%$ Triton X-100 in phosphate-buffered saline (PBS) was applied for $20 \mathrm{~min}$. Consequently, cells were blocked by $5 \%$ goat serum for $1 \mathrm{~h}$ at room temperature. $\mathrm{CDH} 1, \mathrm{NF}-\kappa \mathrm{B}$ and TP63 protein expression of cell lines were detected using anti-CDH1 (Abcam, Cambridge, MA, USA), anti-NF- $\mathrm{kB}$ 
(Cell Signaling, Tokyo, Japan) and anti-TP63 (Santa Cruz Biotechnology, Santa Cruz, CA, USA) antibody according to the manufacturer's protocol. Alexa Fluor-conjugated antibody was used as a secondary antibody.

Target gene prediction. Target genes prediction was performed to meet the following criteria. First, miRNA targets were analyzed using three algorithms, including TargetScan (http://www.targetscan.org) and microRNA.org (http://www. microrna.org/). Second, in order to reduce the number of false positives, only putative target genes predicted by at least two of the programs were accepted.

Transient transfections of TP63-shRNA. To knock down endogenous TP63 in Panc-1 and BxPC-3, the cells were both seeded at 70-80\% confluence in 6-well plates. TP63 and negative control shRNAs were purchased from Invitrogen. Two different shRNAs were transfected at a final concentration of $80 \mathrm{nM}$ per well using Lipofectamine RNAiMAX reagent (Invitrogen) following the manufacturer's recommendations. To validate suppression efficiency of shRNA, cells were incubated for $48 \mathrm{~h}$ and then harvested for real-time PCR analysis. Subsequently, mixed shRNAs were transfected in both cell lines respectively. For immunofluorescence, the cells were seeded into chamber slides. After 48-h transfection, cells were fixed with $4 \%$ paraformaldehyde. Details as given above.

$N F-\kappa B$ inhibition using $I \kappa B-\alpha$ mutant adenovirus in Panc- 1 and $B x P C-3$ cells. To investigate the association with $\mathrm{NF}-\kappa \mathrm{B}$ and $\mathrm{CDH} 1, \mathrm{NF}-\kappa \mathrm{B}$ activation was downregulated by $\mathrm{I} \kappa \mathrm{B}-\alpha$ mutant adenovirus in Panc-1 and BxPC-3 cells. Both viruses were purchased from Vector Biolabs (Philadelphia, PA, USA). Cells were seeded in a 6-well plate at 70-80\% confluence. Twelve hours later, mutant and the control adenovirus were infected at a MOI (multiplicity of infection) of 100 for serial two days in the cells, respectively. Then, the RNA was extracted for real-time PCR analysis for CDH1 expression.

Activation of $N F-\kappa B$ by lipopolysaccharide (LPS) in miR-301b knock-down cells. To further examine the association with $\mathrm{NF}-\kappa \mathrm{B}$ and CDH1, LPS (Sigma-Aldrich, St. Louis, MO, USA) was added to activate NF- $\mathrm{BB}$. Cells were seeded in a 6 -well plate at $70-80 \%$ confluence. After $12 \mathrm{~h}, \mathrm{miR}-301 \mathrm{~b}$ or negative control viruses were transfected at $50 \mathrm{nM}$ using RNAiMax (Invitrogen). Forty-eight hours later, LPS was added in each well at $0,2.5$ and $5 \mu \mathrm{g} / \mathrm{ml}$ for $2 \mathrm{~h}$. Then, the RNA was extracted for real-time PCR analysis for CDH1 expression.

Statistical analysis. All results were performed in triplicate and carried out on at least two times. Data are shown as the mean \pm SD where applicable. Graphpad Prism v5.0 (Graphpad Software Inc., La Jolla, CA, USA) was used for all statistical analysis. Levels of significance for comparison between cell lines were determined by the Student's t-test distribution. To assess the correlation between miR-301b expression, TP63 expression and CDH1 expression, Pearson correlation analysis was performed in pancreatic carcinoma cell lines. The probability of $\mathrm{P}<0.05$ was considered to be statistically significant.

\section{Results}

$M i R-301 b$ regulated invasiveness and promoted gemcitabine resistance in Panc-1 and BxPC-3 cells. To evaluate functional role of miR-301b in pancreatic carcinoma, pre miR-301b or miR-301b inhibitor were transfected in Panc-1 and BxPC-3 cells using lipofectamine. Efficacy of transfection was confirmed by real-time PCR (Figs. 1A and 2A). MiR-301b inhibitor transfection suppressed their invasiveness, while inhibition of miR-301b did not affect sensitivity to gemcitabine (Fig. 1B and C). On the other hand, miR-301b precursor molecules enhanced invasiveness in both cell line types. Moreover, miR-301b transfection increased gemcitabine resistance (Fig. $2 \mathrm{~B}$ and $\mathrm{C}$ ). Next, migration ability was evaluated by the wound healing assay. We transiently inhibited or forced miR-301b expression in both cells. Inhibition of miR-301b reduced migration (Fig. 1D). On the other hand, forced miR-301b promoted the migration ability compared to control transfected cells (Fig. 2D). These results were consistent in both cell lines. Transfected cells did not show any change by the proliferation assay in either cell line (data not shown).

MiR-301b expression level was inversely correlated with CDH1 expression. MiR-301b inhibition exhibited increased CDH1 expression at mRNA level compared to control in Panc-1 cells. Then immunofluorescence was performed for CDH1. MiR-301b knock-down cells showed enhanced CDH1 protein in Panc-1 cells. Inversely, overexpressed miR-301b cells showed reduced CDH1 expression levels. To validate this phenomenon, real-time PCR and immunofluorescence experiments were carried out in BxPC-3 cells. We obtained the same results with Panc-1 cells (Fig. 3). However, morphology remained unchanged in miR-301b overexpression and knock-down cells (data not shown). We also measured epithelial to mesenchymal transition (EMT)related genes, such as Vimentin, Snail, Slug, Twist, Zeb1 and Zeb2 by real-time PCR. Unfortunately, the results did not exhibit consistent pattern of such gene expression to explain how miR-301b affected CDH1 expression in the cell lines (data not shown).

TP63 is suggested as a potent target for miR-301b. We explored candidates of miR-301b target using miRNA target search algorithms which were available at TargetScan and microRNA.org. There were 2,136 and 7,903 potential targets respectively. Among the putative considerable targets, we focused on specific genes which were associated with CDH1 expression. We chose PTEN and TP63 as potential targets of miR-301b. Initially, to identify pathways which are involved in miR-301b, we investigated the miR-301b, TP63, PTEN and CDH1 expression using five different cell lines (Panc-1, MIAPaCa-2, BxPC-3, Capan-2 and Hpaf-2) by realtime PCR method. Interestingly, the result showed a clear inverse correlation between miR-301b and TP63 expression in Pearson data $\left(r^{2}=0.7961\right)$ (Fig. 4A). However, there was no correlation in miR-301b-PTEN, PTEN-CDH1 and TP63-CDH1 relation, respectively (data not shown). These data indicated that TP63 was one of the putative targets for miR-301b. Therefore, we hypothesized a possible pathway 

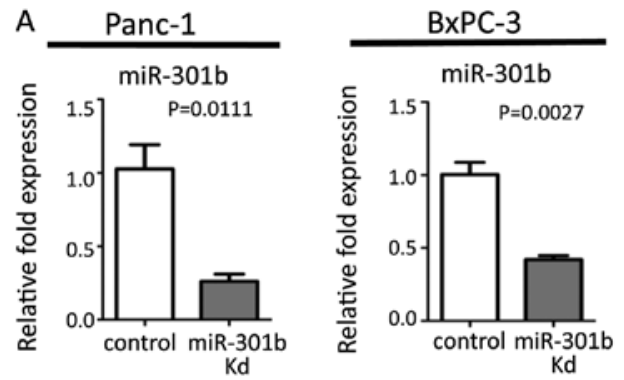

B

Gemcitabine sensitivity $(0.2 \mu \mathrm{M})$

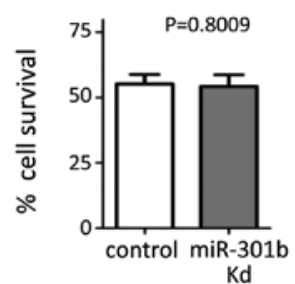

C
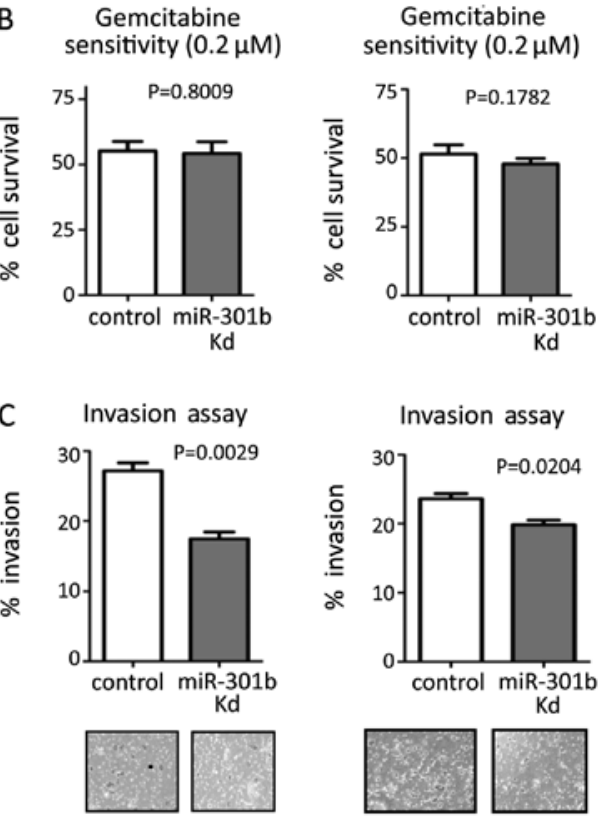

Invasion assay

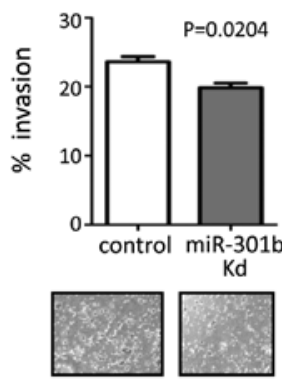

D-1

Panc-1

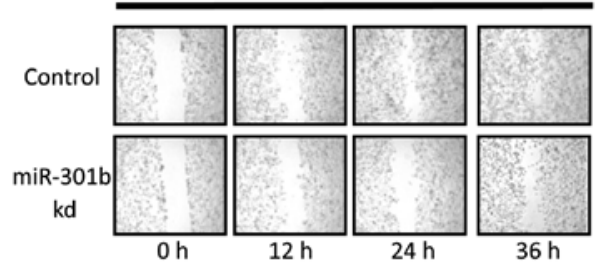

D-2

BxPC-3

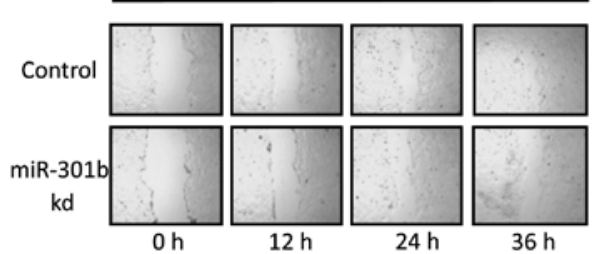

Figure 1. Functional analysis of pancreatic carcinoma cells when miR-301b was downregulated using miR-301b inhibitor. (A) MiR-301b inhibitor (miR-301b Kd) was transfected in Panc-1 and BxPC-3 cells. Inhibition efficiency was examined by real-time PCR. MiR-301b levels were expressed as relative fold change. Data represent the average of triplicates and are representative of three independent experiments. (B) Gemcitabine sensitivity assay was performed by colorimetric assay at $\mathrm{IC}_{50}$ of the respective control gemcitabine ( 0.2 and $0.01 \mu \mathrm{M})$ for $96 \mathrm{~h}$ in Panc-1 and BxPC-3 cells. (C) After transfection of $50 \mathrm{nM}$ miR-301b inhibitor (miR-301b Oe) or control, cells were seeded into Matrigel-coated chamber for invasion assays. After fixation by methanol, invaded cells were stained by crystal violet and photographed. Then, invaded cells were counted in 3 separate microscopic fields per well, which were averaged and the mean values per well \pm SD were calculated from triplicate wells. (D) Panc-1 and BxPC-3 cells were seeded in a 6-well plate and transfected with a $50 \mathrm{nM}$ miR-301b inhibitor (miR-301b Kd) or control. Images of the migration area were captured at $0,12,24,36$ and $48 \mathrm{~h}$ after overnight transfection.
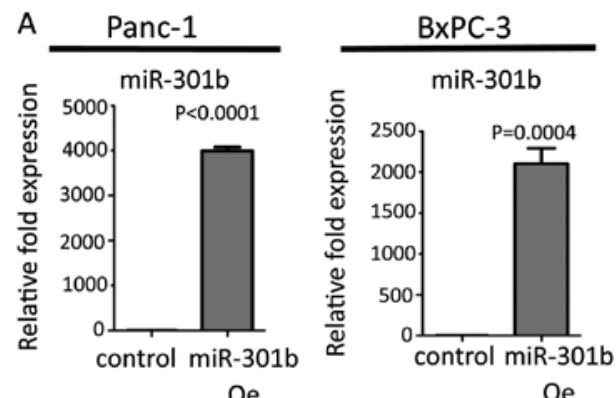
B Gemcitabine
sensitivity $(0.2 \mu \mathrm{M})$

Gemcitabine sensitivity $(0.2 \mu \mathrm{M})$
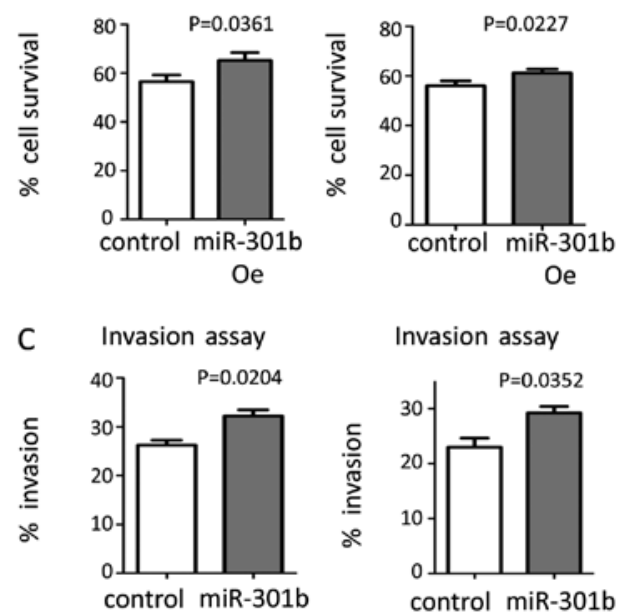

Invasion assay
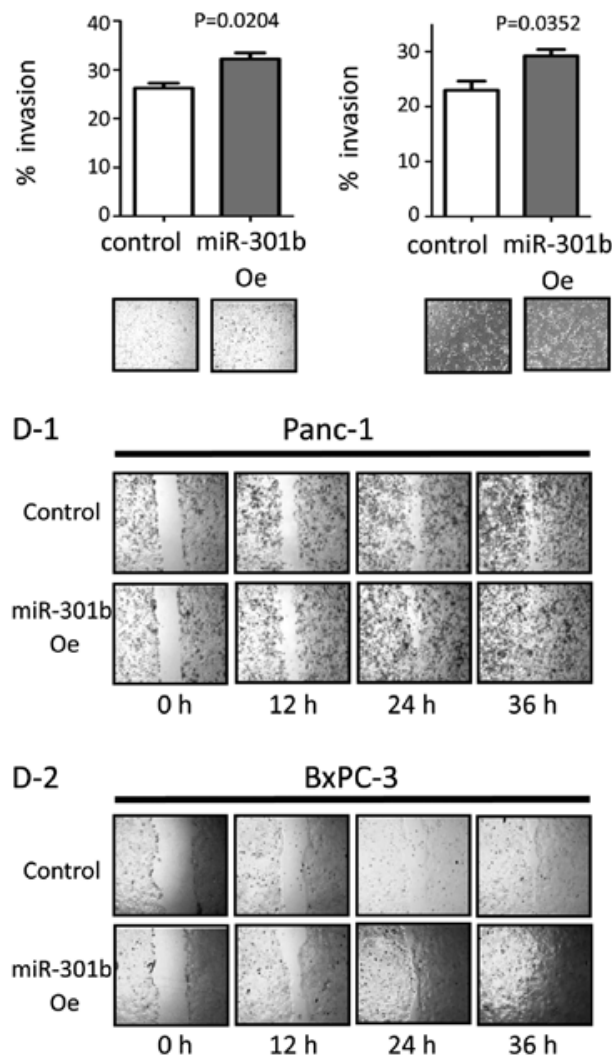

Figure 2. Functional analysis of pancreatic carcinoma cells when miR-301b was upregulated using pre-miR-301b. (A) Pre-miR-301b (miR-301b Oe) was transfected in Panc-1 and BxPC-3 cells. Transduction efficiency was examined by real-time PCR. MiR-301b levels were expressed at relative fold change. Data represent the mean of three replicates \pm SED. These data are representative of three independent experiments. (B) Transfected cells with pre-miR-301b (miR-301b Oe) or control were seeded in a 96-well plate at 4,000 or 5,000 cells/well. After $96 \mathrm{~h}$ gemcitabine sensitivity assay was performed by colorimetric assay at $\mathrm{IC}_{50}$ of the respective control gemcitabine $(0.2$ and $0.01 \mu \mathrm{M})$ in Panc-1 and BxPC-3 cells. (C) After transfection of premiR-301 (miR-301b Oe) or control, cells were seeded for invasion assays. Invaded cells were stained by crystal violet and photographed. Then, invaded cells were counted in 3 separate microscopic fields per well, which were averaged, and the mean values per well \pm SD were calculated from triplicate wells. (D) Panc-1 and BxPC-3 cells were seeded in a 6-well plate and transfected with $50 \mathrm{nM}$ pre-miR-301b (miR-301b Oe) or control. Images of the migration area were captured $0,12,24,36$ and $48 \mathrm{~h}$ after transfection overnight. 

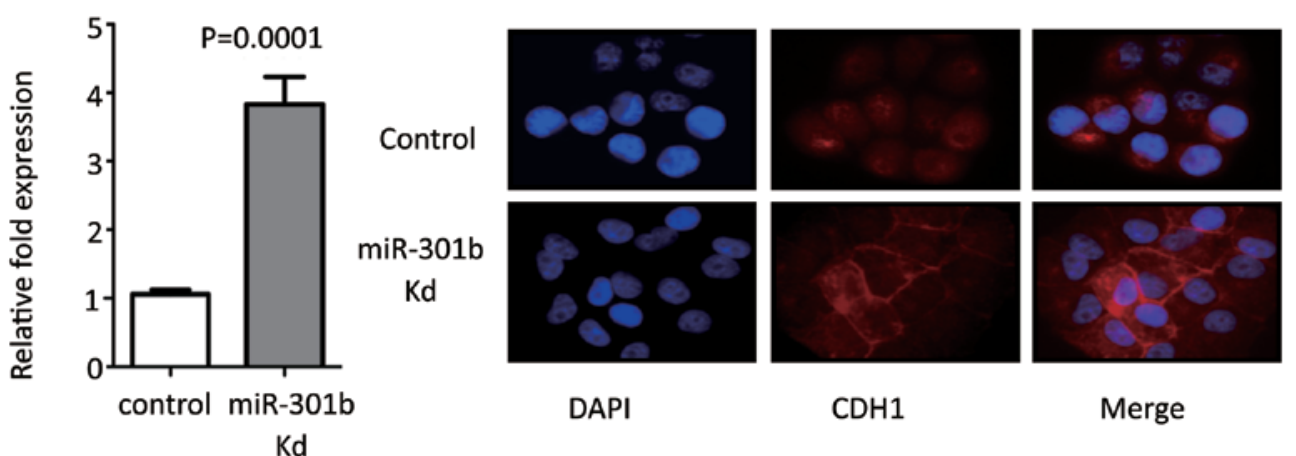

DAPI

$\mathrm{CDH} 1$

Merge
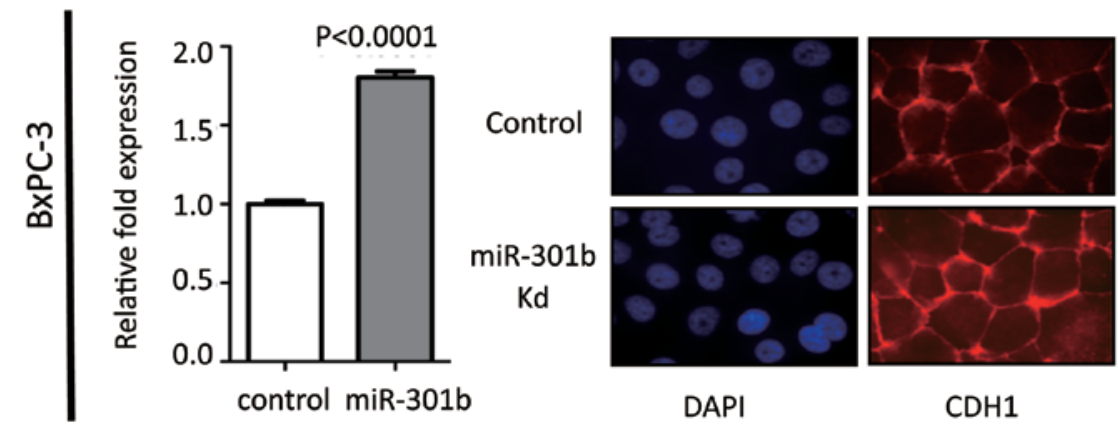

DAPI

$\mathrm{CDH} 1$

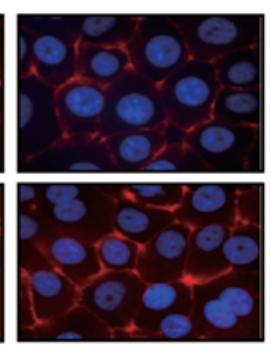

Merge

$$
\text { B }
$$
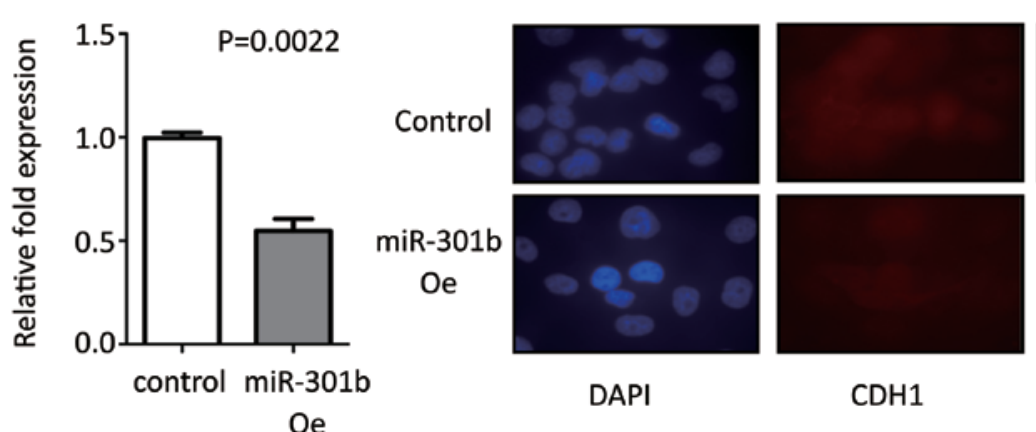

DAPI

$\mathrm{CDH} 1$

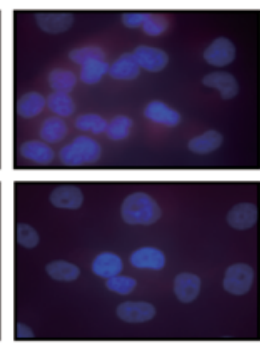

Merge
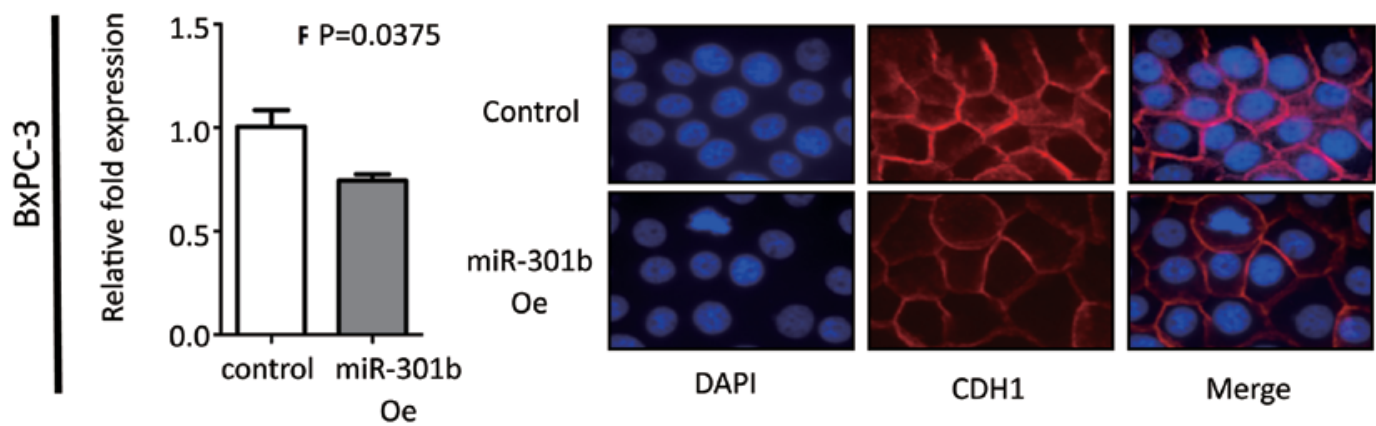

Figure 3. MiR-301b inversely regulates CDH1 expression in pancreatic carcinoma cells. (A) MiR-301b inhibition (miR-301b Kd) increased CDH1 at mRNA and protein levels in Panc-1 and BxPC-3 cells, respectively. (B) Mir-301b overexpression decreased CDH1 compared to control cells in both cell types. Realtime PCR data represent the mean of three biological replicates. Immunostaining data are representative of two independent experiments.

to demonstrate how miR-301b regulates CDH1 expression (Fig. 4B).

MiR-301b regulates TP63 as one of several miR-301b target genes in pancreatic carcinoma. Further study revealed that miR-301b transfection attenuated endogenous TP63 expression relative to control cells in Panc-1 and BxPC-3 cells (Fig. 5B).
In contrast, downregulated miR-301b demonstrated increased TP63 expression in both cell lines as well (Fig. 5A). These results suggested that TP63 was the most likely candidate to have interaction with miR-301b.

MiR-301b expression level is associated with NF- $\kappa \mathrm{B}$ activity. In miR-301b-inhibited cells, we found that $N F-\kappa B$ was downregulated in Panc-1 and BxPC-3. Moreover, when 


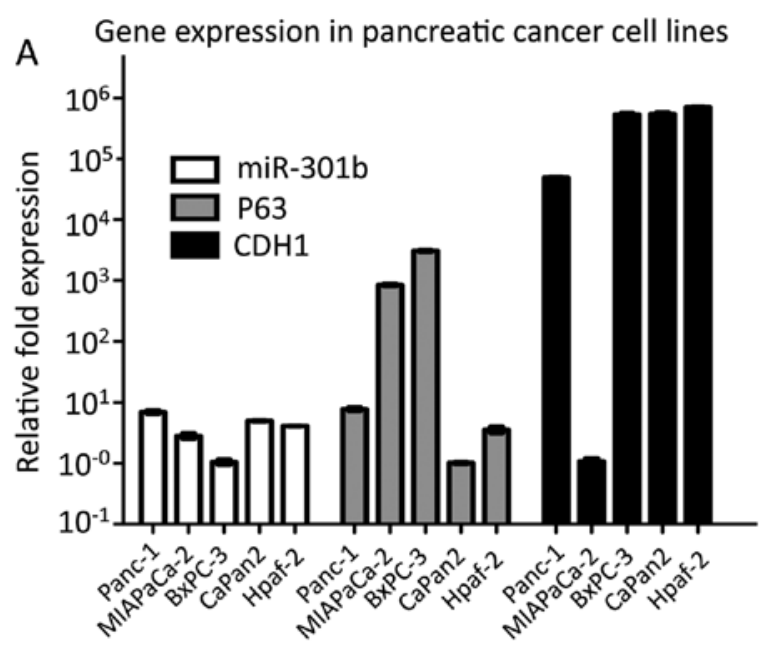

B

Correlation in pancreatic cancer cell lines

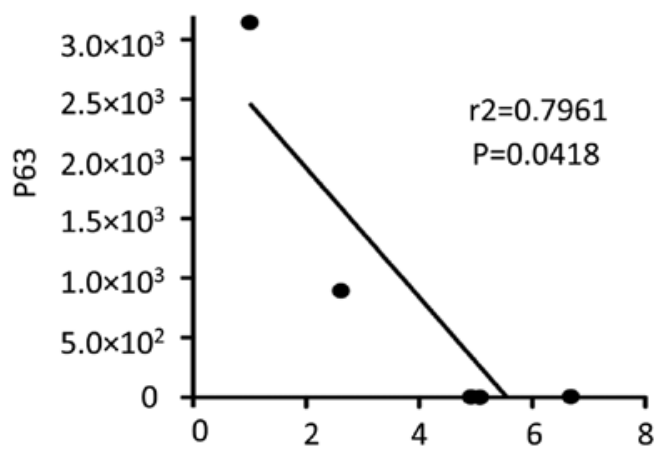

Correlation in pancreatic cancer cell lines

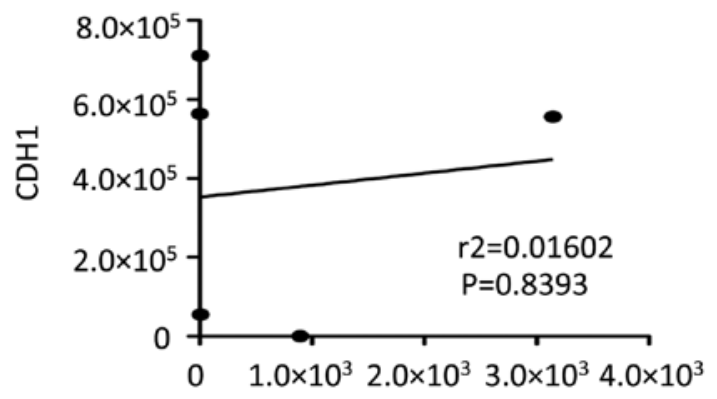

TP63-3' UTR 5' ...UGAAAGAAAAUUGAGUUGCACUU... III \|\|\|\|

hsa-miR301b 3' CGAAACUGUUAUAGUAACGUGAC

Figure 4. MiRNA target search algorithm and pancreatic carcinoma cell line data indicated that miR-301b might directly target TP63. (A) MiR-301b, TP63 and CDH1 mRNA were measured by real-time PCR in five different pancreatic carcinoma cell lines (Panc-1, MIAPaCa-2, BxPC-3, Capan-2 and Hpaf-2). Moreover, their correlation was evaluated using Pearson correlation analysis. (B) Target scan result showed 3'UTR of TP63 is highly conserved and predicted binding sites for miR-301b.

pre-miR-301b was transfected, NF- $\kappa \mathrm{B}$ moved into nucleus from cytoplasm in both cell lines (Fig. 6A). To further study miRNA-mediated NF- $\kappa \mathrm{B}$ activation in pancreatic carcinoma cells, endogenous TP63 was repressed by TP63 shRNA. In both cell lines, inhibition efficiency showed $\geq 60 \%$ inhibition at each shRNA. TP63 knock-down cells exhibited activated $\mathrm{NF}-\kappa \mathrm{B}$ by immunofluorescence analysis and downregulated CDH1 by real-time PCR and immunofluorescence analysis (Fig. 6B).

$N F-\kappa B$ regulated $C D H 1$ expression. To examine our putative pathway (Fig. 7A), NF- $\kappa$ B was suppressed using I $\mathrm{B}-\alpha$ mutant adenovirus. When Panc- 1 and BxPC-3 cells were infected with adenovirus, $\mathrm{CDH} 1$ was slightly upregulated. In contrast, when $\mathrm{NF}-\kappa \mathrm{B}$ was activated by lipopolysaccharide (LPS) in miR-301 knock-down cells, NF- $\kappa \mathrm{B}$ activation by LPS significantly negated the beneficial effect on upregulation of CDH1 by miR$301 \mathrm{~b}$ inhibition (Fig. 7B). These data suggested that the NF- $\kappa \mathrm{B}$ regulates $\mathrm{CDH} 1$ expression.

\section{Discussion}

Deregulated expression of miRNAs is responsible for cancer initiation and development in many types of cancer. Recent reports have revealed that aberrant expression of miRNAs is implied in cell proliferation, cell invasion and chemo-sensitivity. Among these miRNAs, there is accumulated evidence suggesting that miR-301 is upregulated in several malignant tumors $(11,14,15)$. Furthermore, functional role of miR-301 has been reported $(16,17)$. Shi et al demonstrated that miR-301 overexpression is implicated as a negative prognostic factor in lymph node-negative invasive ductal breast cancer. They also showed that miR-301 attenuation decreased cell proliferation, clonogenicity, migration, invasion, tamoxifen resistance, tumor growth, and microvessel density through targeting FOXF2, BBC3, PTEN, and COL2A1 (17). In addition, Cao et al showed that miR-301 targeted MEOX2 to affect the ERK/CREB pathway in a lung carcinoma cell line (16). A recent study in pancreatic carcinoma demonstrated that miR-301a contributed to activation of $\mathrm{NF}-\kappa \mathrm{B}$ by repressing NKrf which interacted with specific negative regulatory elements to mediate transcriptional repression of $\mathrm{NF}-\kappa \mathrm{B}$ (18). These findings indicate that miR-301 may function as an oncogene by inhibiting tumor suppressor genes.

In this study we focused on investigating how miR-301b regulated invasiveness of pancreatic carcinoma, since miR-301b attenuation showed reduced invasiveness. Moreover, exogenous miR-301b enhanced invasiveness in both Panc-1 and BxPC-3 cell lines. Consistent with previous report in breast cancer (17), our data showed similar results even in pancreatic carcinoma cell lines. As a factor of enhanced invasiveness, we found that CDH1 might be a candidate to explain the phenomenon among the epithelial to mesenchymal transition (EMT)-related gene expression, such as CDH1, Vimentin, Zeb1, Zeb2, Twist, Snail and Slug, which were measured using real-time PCR when miR-301b was forced or inhibited in both Panc-1 and BxPC-3 cells. However, miR-301b expression level did not affect their morphology in spite of alteration of CDH1 expression (data not shown). To investigate the mechanism how miR-301b could influence CDH1 expression using TargetScan and microRNAs.org prediction tools for possible mRNA targets, we selected two genes, PTEN and TP63 on the condition that: i) the target has to overlap with both algorithms, ii) the target 

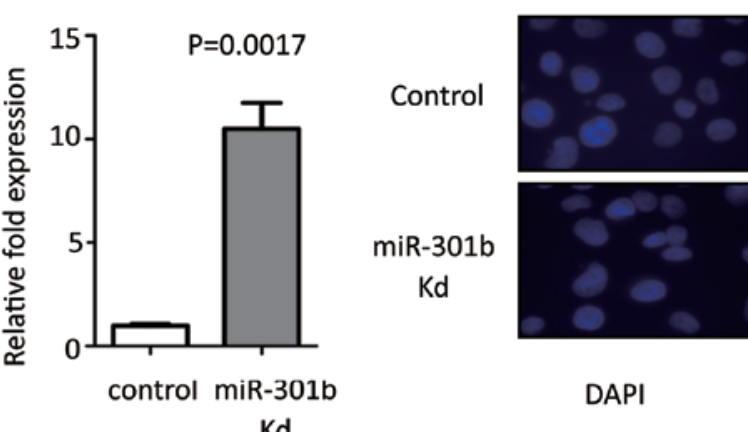

DAPI

$\mathrm{Kd}$
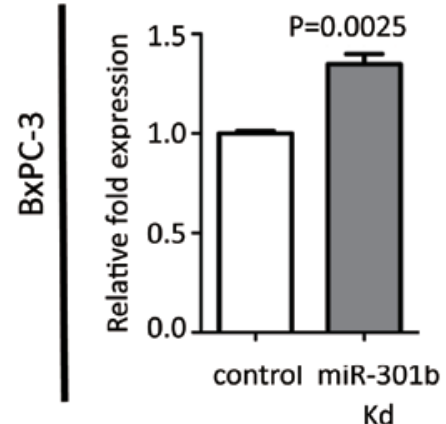

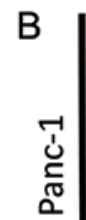

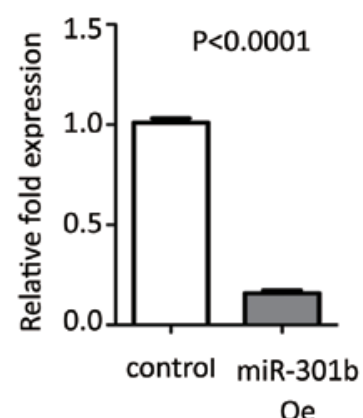

$\mathrm{Oe}$
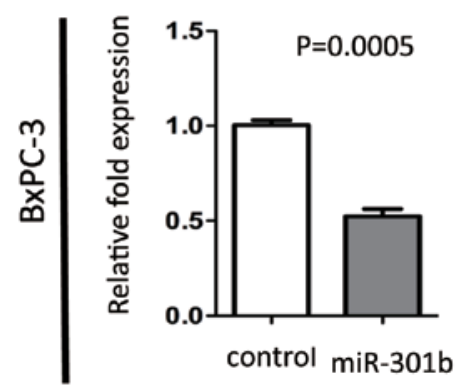

Oe

miR-301b

Kd

DAPI

DAPI

miR-301b

$\mathrm{Oe}$

DAPI

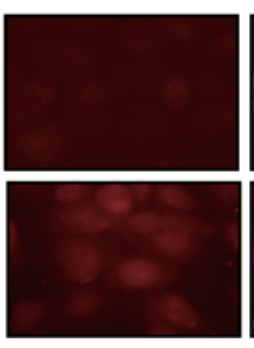

$\mathrm{CDH} 1$
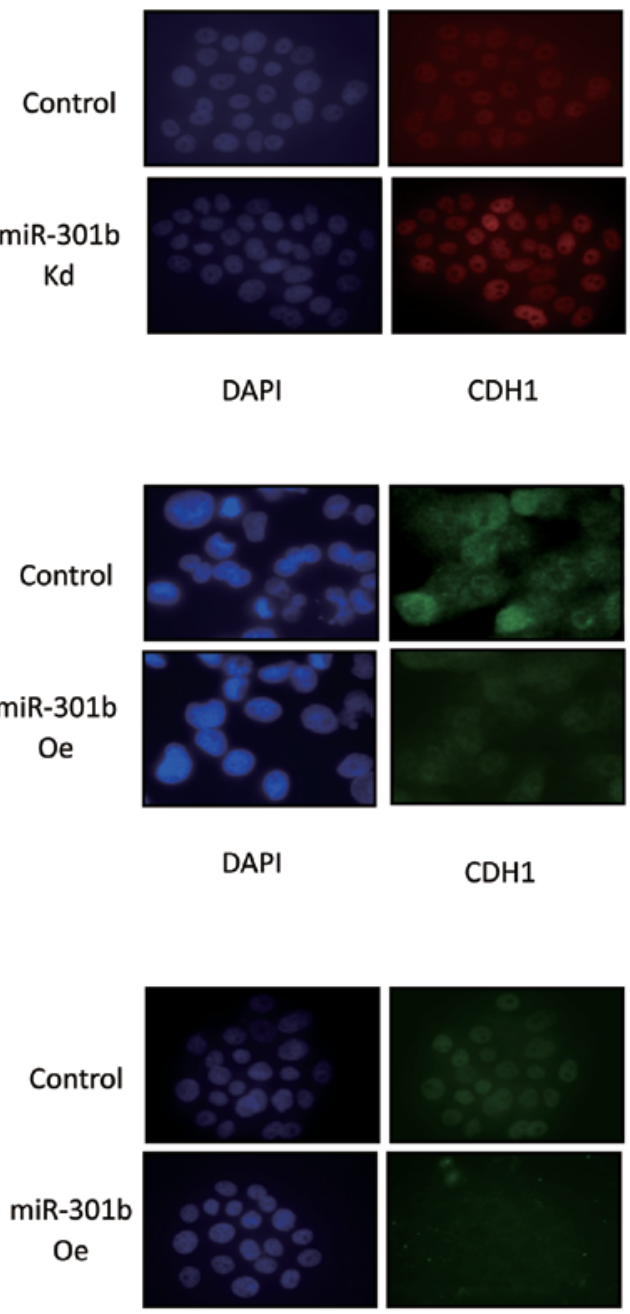
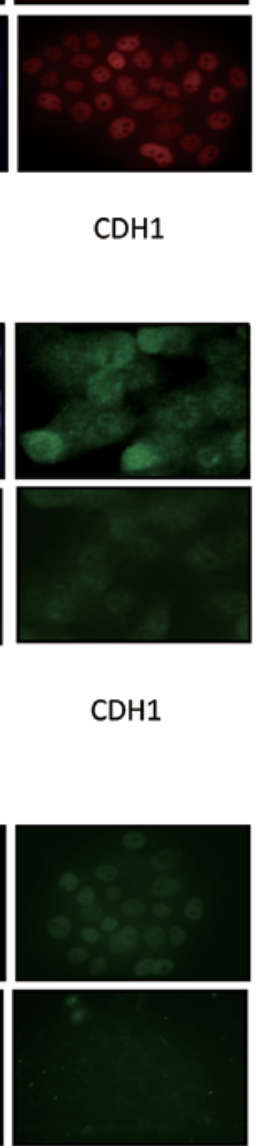

$\mathrm{CDH} 1$
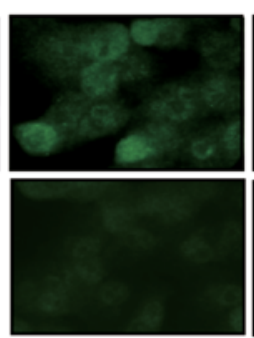

$\mathrm{CDH} 1$

$\mathrm{CDH} 1$
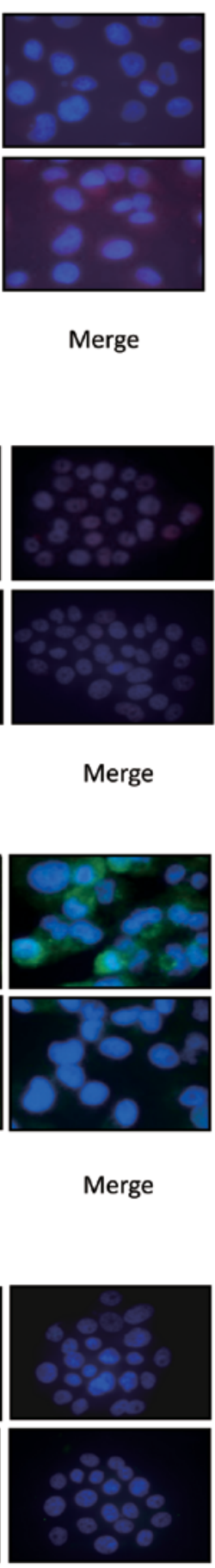

Merge
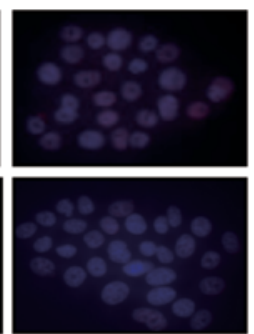

Merge

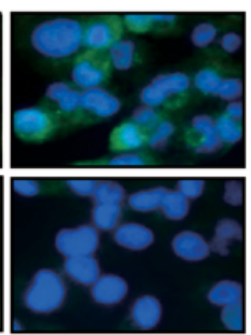

Merge

Merge

Figure 5. Forced/reduced miR-301b experiments in Panc-1 and BxPC-3 cells, respectively. (A) MiR-301b inhibitor (miR-301b Kd) or control was transfected at $50 \mathrm{nM}$ in a 6 -well plate and 4 chamber slides for $48 \mathrm{~h}$. For real-time PCR, cells were lysed and collected as described in Materials and methods. Immunostaining was performed for TP63. The result showed that miR-301b inhibition leads to enhanced TP63 expression in both Panc-1 and BxPC-3 cells. All quantitative values are the mean \pm SD. (B) MiR-301b overexpression (miR-301b Oe) reduced mRNA level of TP63 in Panc-1 and BxPC-3 cells. Immunostaining shows TP63 was strongly suppressed in miR-301b overexpressed cells as well.

has to be a tumor suppressor gene, and iii) the target has to be associated with CDH1. PTEN was already published as a target of miR-301 in breast cancer (17). However, in our data, PTEN expression was not associated with miR-301b expression level in pancreatic carcinoma cells (data not shown). Therefore, we examined TP63 as a novel putative target of
miR-301b. i) Statistical analysis demonstrated strong correlation between CDH1 and miR-301b $\left(\mathrm{r}^{2}=0.7961, \mathrm{P}=0.0418\right)$ in five pancreatic carcinoma cell lines. ii) Forced expression/ knock-down miR-301b reduced/induced TP63 expression. According to these findings, we concluded that TP63 is a new potential target for miR-301b. 
A
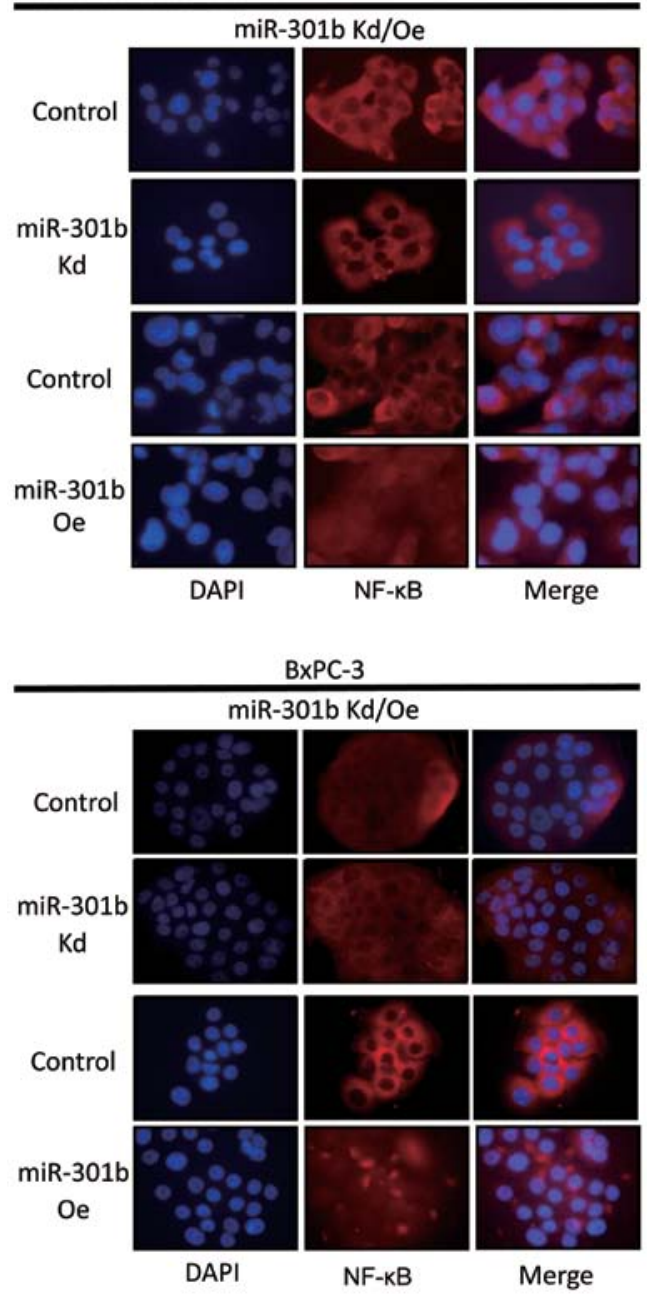

B

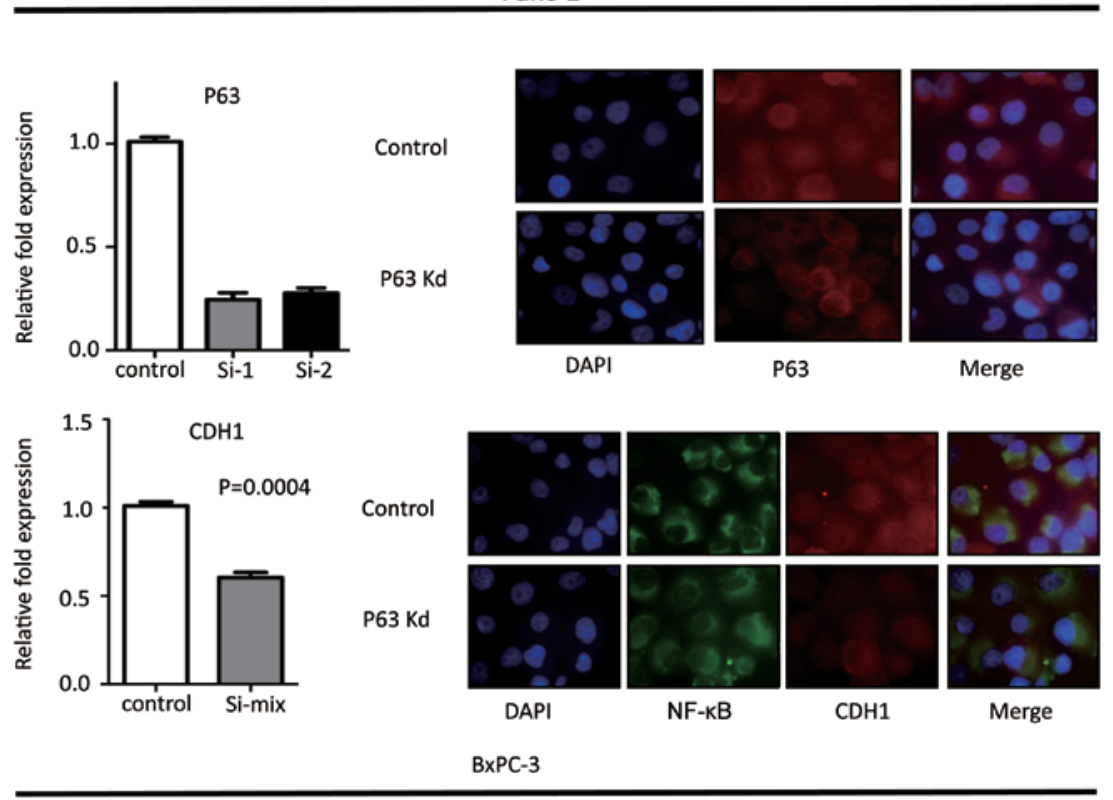

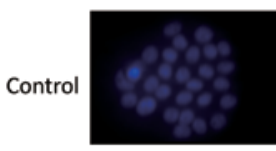
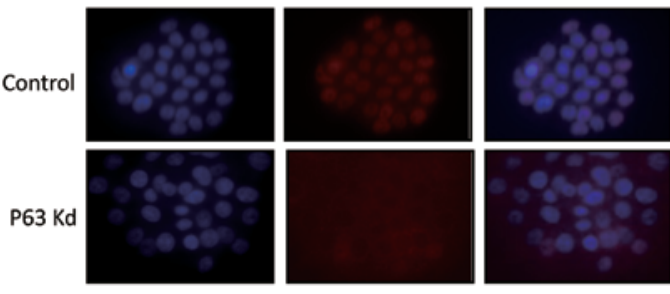

DAPI

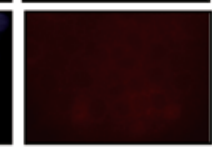

P63
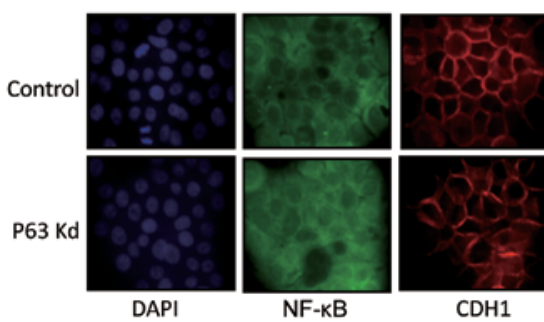

$\mathrm{CDH} 1$

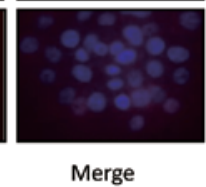

Merge

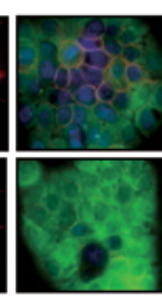

Figure 6. Immunostaining suggests miR-301b was implicated in NF- $\kappa$ B activity in both Panc-1 and BxPC-3 cells. (A) MiR-301b inhibition (miR-301b Kd) induced more translocation of P65 into the cytoplasm. In contrast, miR-301b forced expression (miR-301b Oe) activated NF- $\mathrm{B}$ activity. P65 moved into the nucleus compared to control cells. Representative images of two independent experiments are shown. (B) Transient knock-down of TP63 resulted in downregulation of CDH1 expression by real-time PCR in both Panc-1 and BxPC-3 cell lines. Immunostaining shows that TP63 inhibition reduced CDH1 and activated $\mathrm{NF}-\kappa \mathrm{B}$.

TP63, which is a member of the P53 tumor suppressor gene family, is critical for the development of stratified epithelial tissues, such as epidermis, breast $(20,21)$ and for cell viability (22). TP63 gene is transcribed from two different promoters, generating two types of isoforms which either contain or lack an amino-terminal transactivation domain referred to as TA and $\Delta \mathrm{N}$ isoforms, respectively. TAp63 has been implicated in regulation of cell proliferation, apoptosis and differentiation. Elevated TAp63 has several functions inducing p53-responsive genes, inhibiting cell proliferation and promoting apoptosis (23). Inhibition of TAp63 induced chemoresistance (24). TAp63 isoforms acted as tumor suppressors by regulating senescence through p53-independent pathways (25), whereas $\Delta \mathrm{Np63}$ isoforms enhance proliferation and inhibit apoptosis
$(26,27)$. A recent report showed that TAp63 regulates $\mathrm{NF}-\kappa \mathrm{B}$ transcription and protein stability, subsequently leading to the cell death phenotype (28). Another report showed TAp63 is a transcriptional target of $\mathrm{NF}-\kappa \mathrm{B}$, which may play a role in cell proliferation, differentiation and survival upon $\mathrm{NF}-\kappa \mathrm{B}$ activation $(29,30)$. In contrast, $\mathrm{NF}-\kappa \mathrm{B}$ repressed $\mathrm{CDH} 1$ expression through enhancing Zeb1 expression (31). Based on this evidence, we hypothesized that miR-301b regulates $\mathrm{CDH} 1$ expression through TP63 and NF- $\kappa \mathrm{B}$ (Fig. 7A). Overexpressed miR-301b cells exhibited more activated NF- $\kappa$ B than control cells in both pancreatic carcinoma cell lines. Furthermore, TP63 inhibition by shRNA showed activated NF- $\kappa$ B and reduced $\mathrm{CDH} 1$ expression. On the other hand, $\mathrm{NF}-\kappa \mathrm{B}$ inhibition using I $\kappa \mathrm{B}-\alpha$ mutant adenovirus revealed elevated CDH1. 
A

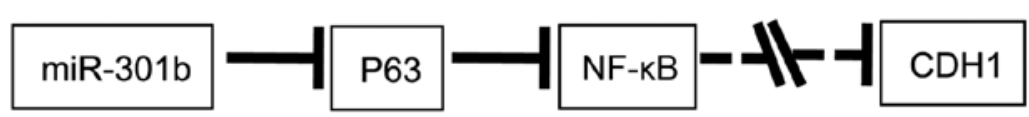

B |

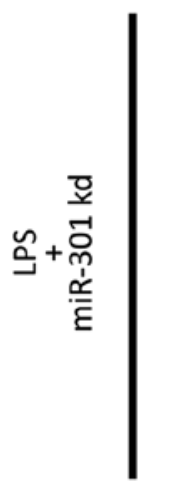

Panc-1
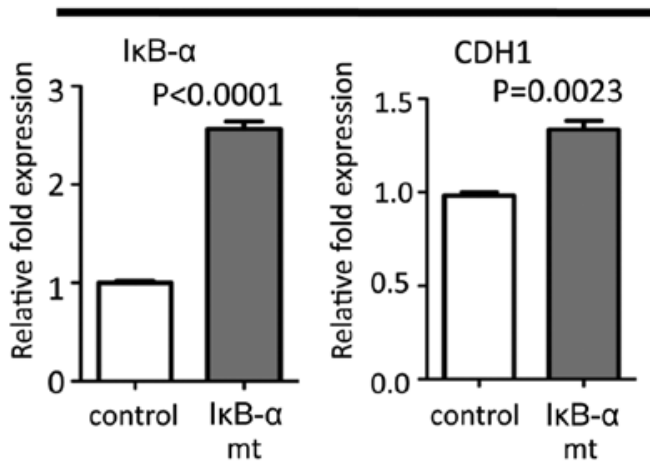

Activated NF-KB by LPS

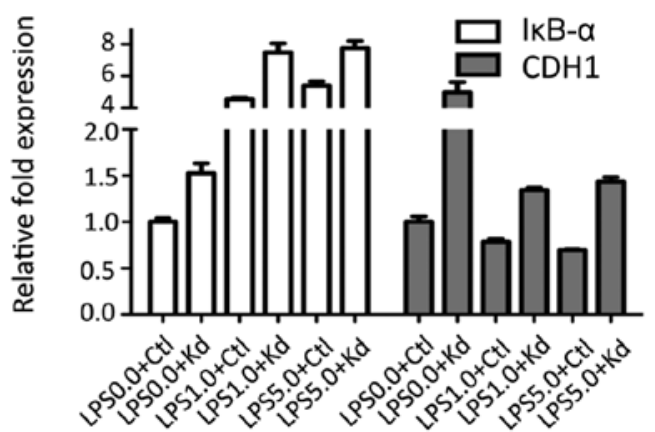

BxPC-3
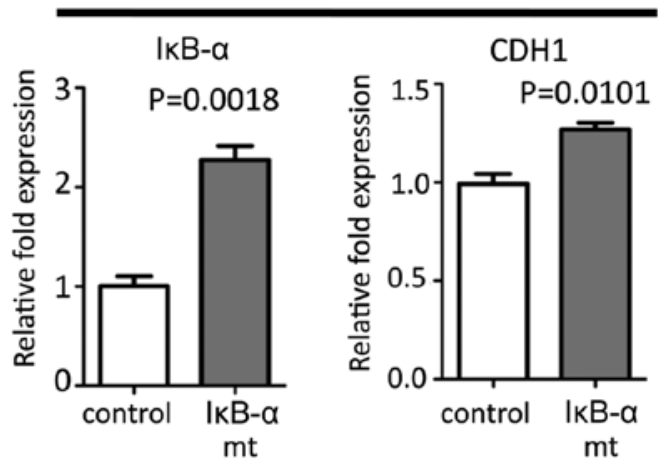

Activated NF-KB by LPS

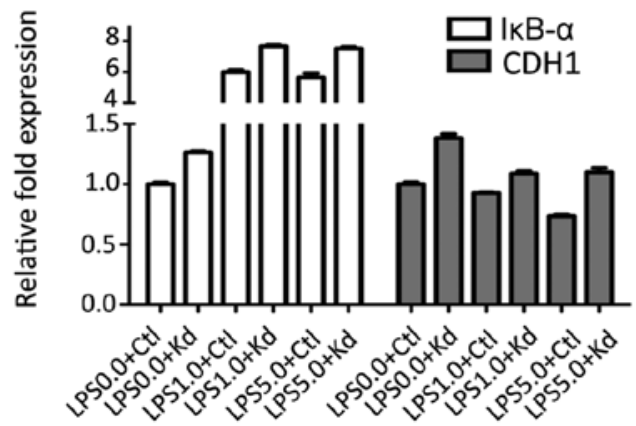

Figure 7. MiR-301b might control CDH1 expression through TP63/NF-kB pathway. (A) Putative pathway for the association between miR-301b and CDH1.

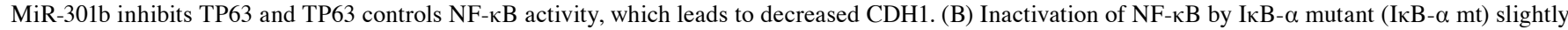
enhanced CDH1 expression. On the contrary, activation of NF-kB by lipopolysaccharide (LPS) downregulated CDH1 expression. Moreover, LPS strongly repressed even increased CDH1 by miR-301b inhibitor.

In addition, NF- $\kappa \mathrm{B}$ activation by lipopolysaccharide (LPS) induced downregulated $\mathrm{CDH} 1$ expression in both cell lines. Effect of LPS on NF- $\mathrm{kB}$ compensated for upregulated CDH1 expression by miR-301b inhibition. Considering these data, TP63 might control CDH1 expression through NF- $\kappa \mathrm{B}$ activation. However, unlike previous published data (31), our data did not show an association between NF- $\mathrm{kB}$ and Zeb1/CDH1 axis. Contrary to our expectations, activation/inactivation of NF- $\mathrm{KB}$ did not show any major change in $\mathrm{CDH} 1$ expression in either cell line, and TP63 did not have any significant correlation with $\mathrm{CDH} 1$ in five different cell line data. These data suggested that NF- $\kappa \mathrm{B}$ does not regulate $\mathrm{CDH} 1$ expression exclusively through Zeb1, but also through other transfactors. Our results indicated that miR-301b expression contributed to NF- $\kappa B$ activation in pancreatic carcinoma, which was the same as previous reports, however, the target to regulate NF- $\kappa \mathrm{B}$ was different (18). Consistent with some published findings, our results supported the hypothesis that miR-301b might suppress $\mathrm{CDH} 1$ through the TP63/NF- $\mathrm{BB}$ pathway as an oncogene in pancreatic carcinoma. Hence, with increased amount of evidence toward an explanation for pancreatic carcinoma, treatment tailored to each individual's gene profiling will be extremely desired $(32,33)$. The limitations of our study include the unclear mechanism how TP63 regulates $\mathrm{CDH} 1$ expression through NF- $\mathrm{KB}$, and lack of a mouse study.

In conclusion, our data indicated that TP63 could be targeted by miR-301b in pancreatic carcinoma. Our data suggested that miR-301b might be useful as a biomarker of malignant potential. We also demonstrated that miR-301b promotes cell invasion through inhibition of $\mathrm{CDH} 1$ by targeting the tumor suppressor gene TP63 in pancreatic carcinoma. Finally, exogenous miR-301b was involved in gemcitabine resistance. These data indicated that tailored treatments according to gene expression in each patient will be employed for treatment of pancreatic carcinoma in the near future.

\section{Acknowledgements}

The authors would like to thank Dr Mitsuhiro Yoneda for helpful discussions throughout this study. 


\section{References}

1. Jemal A, Siegel R, Ward E, Hao Y, Xu J, et al: Cancer statistics, 2009. CA Cancer J Clin 59: 225-249, 2009.

2. Eltawil KM, Renfrew PD and Molinari M: Meta-analysis of phase III randomized trials of molecular targeted therapies for advanced pancreatic cancer. HPB (Oxford) 14: 260-268, 2012.

3. Li D, Xie K, Wolff R and Abbruzzese JL: Pancreatic cancer. Lancet 363: 1049-1057, 2004.

4. Bartel D: MicroRNAs: genomics, biogenesis, mechanism, and function. Cell 116: 281-297, 2004.

5. Piepoli A, Tavano F, Copetti M, Mazza T, Palumbo O, et al: MiRNA expression profiles identify drivers in colorectal and pancreatic cancers. PLoS One 7: e33663, 2012.

6. Nikitina EG, Urazova LN and Stegny VN: MicroRNAs and human cancer. Exp Oncol 34: 2-8, 2012.

7. Iorio MV and Croce CM: MicroRNA dysregulation in cancer: diagnostics, monitoring and therapeutics. A comprehensive review. EMBO Mol Med 4: 143-159, 2012.

8. Li C, Hashimi SM, Good DA, Cao S, Duam W, et al: Apoptosis and microRNA aberrations in cancer. Clin Exp Pharmacol Physiol 39: 739-746, 2012.

9. Garofalo M, Romano G, Di Leva G, Nuovo G, Jeon YJ, et al: EGFR and MET receptor tyrosine kinase-altered microRNA expression induces tumorigenesis and gefitinib resistance in lung cancers. Nat Med 18: 74-82, 2011.

10. Wu Y, Xiao Y, Ding X, Zhuo Y, Ren P, et al: A miR-200b/200c/ 429-binding site polymorphism in the 3 ' untranslated region of the AP- $2 \alpha$ gene is associated with cisplatin resistance. PLoS One 6: e29043, 2011.

11. Lee EJ, Gusev Y, Jiang J, Nuovo GJ, Lerner MR, et al: Expression profiling identifies microRNA signature in pancreatic cancer. Int J Cancer 120: 1046-1054, 2007.

12. Jiang J, Gusev Y, Aderca I, Mettler TA, Nagorney DM, et al: Association of MicroRNA expression in hepatocellular carcinomas with hepatitis infection, cirrhosis, and patient survival. Clin Cancer Res 14: 419-427, 2008.

13. Miko E, Czimmerer Z, Csánky E, Boros G, Buslig J, et al: Differentially expressed microRNAs in small cell lung cancer. Exp Lung Res 35: 646-664, 2009.

14. Lu YC, Chen YJ, Wang HM, Tsai CY, Chen WH, et al: Oncogenic function and early detection potential of miRNA-10b in ora cancer as identified by microRNA profiling. Cancer Prev Res 5 : 665-674, 2012.

15. Wang YX, Zhang XY, Zhang BF, Yang CQ, Chen XM and Gao HJ: Initial study of microRNA expression profiles of colonic cancer without lymph node metastasis. J Dig Dis 11: $50-54,2010$.

16. Cao G, Huang B, Liu Z, Zhang J, Xu H, et al: Intronic miR-301 feedback regulates its host gene, ska2, in A549 cells by targeting MEOX2 to affect ERK/CREB pathways. Biochem Biophys Res Commun 396: 978-982, 2010.

17. Shi W, Gerster K, Alajez NM, Tsang J, Waldron L, et al: MicroRNA-301 mediates proliferation and invasion in human breast cancer. Cancer Res 71: 2926-2937, 2011.

18. Lu Z, Li Y, Takwi A, Li B, Zhang J, et al: miR-301a as an NF-кB activator in pancreatic cancer cells. EMBO J 30: 57-67, 2011.
19. Funamizu N, Okamoto A, Kamata Y, Misawa T, Uwagawa T, et al: Is the resistance of gemcitabine for pancreatic cancer settled only by overexpression of deoxycytidine kinase? Oncol Rep 23: 471-475, 2010.

20. Yang A, Kaghad M, Wang Y, Gillett E, Fleming MD, et al: p63, a p53 homolog at 3q27-29, encodes multiple products with transactivating, death-inducing, and dominant-negative activities. Mol Cell 2: 305-316, 1998

21. Yang A, Schweitzer R, Sun D, Kaghad M, Walker N, et al: p63 is essential for regenerative proliferation in limb, craniofacial and epithelial development. Nature 398: 714-718, 1999.

22. Yuan M, Luong P, Hudson C, Gudmundsdottir K and Basu S: c-Abl phosphorylation of $\Delta \mathrm{Np} 63 \alpha$ is critical for cell viability. Cell Death Dis 1: e16, 2010.

23. Helton ES, Zhang $J$ and Chen $X$ : The proline-rich domain in p63 is necessary for the transcriptional and apoptosis-inducing activities of TAp63. Oncogene 27: 2843-2850, 2010.

24. Gressner O, Schilling T, Lorenz K, Schulze Schleithoff E, Koch A, et al: TAp63alpha induces apoptosis by activating signaling via death receptors and mitochondria. EMBO J 24: 2458-2471, 2005.

25. Guo X, Keyes WM, Papazoglu C, Zuber J, Li W, et al: TAp63 induces senescence and suppresses tumorigenesis in vivo. Nat Cell Biol 11: 1451-1457, 2009.

26. Chiang CT, Chu WK, Chow SE and Chen JK: Overexpression of delta Np63 in a human nasopharyngeal carcinoma cell line downregulates CKIs and enhances cell proliferation. J Cell Physiol 219: 117-122, 2009.

27. Schavolt KL and Pietenpol JA: p53 and Delta Np63 alpha differentially bind and regulate target genes involved in cell cycle arrest, DNA repair and apoptosis. Oncogene 26: 6125-6132, 2007.

28. Sen T, Sen N, Huang Y, Sinha D, Luo ZG, et al: Tumor protein p63/nuclear factor $\kappa \mathrm{B}$ feedback loop in regulation of cell death. J Biol Chem 286: 43204-43213, 2011.

29. Wu J, Bergholz J, Lu J, Sonenshein GE and Xiao ZX: TAp63 is a transcriptional target of NF-kappaB. J Cell Biochem 109: 702-710, 2010.

30. Hayden MS and Ghosh S: Shared principles in NF-kappaB signaling. Cell 132: 344-362, 2008.

31. Chua HL, Bhat-Nakshatri P, Clare SE, Morimiya A, Badve S and Nakshatri H: NF-kappaB represses E-cadherin expression and enhances epithelial to mesenchymal transition of mammary epithelial cells: potential involvement of ZEB-1 and ZEB-2. Oncogene 26: 711-724, 2007.

32. Funamizu N, Kamata Y, Misawa T, Uwagawa T, Lacy CR, et al: Hydroxyurea decreases gemcitabine resistance in pancreatic carcinoma cells with highly expressed ribonucleotide reductase. Pancreas 41: 107-113, 2010.

33. Funamizu N, Lacy CR, Fujita K, Furukawa K, Takeyuki M, et al: Tetrahydrouridine inhibits cell proliferation through cell cycle regulation regardless of cytidine deaminase expression levels. PLoS One 7: e37424, 2012. 